\title{
ONTOGENETIC FEATURES OF SONOGRAPHIC INDICATORS OF THE UTERUS IN ACROBATS OF THE UKRAINIAN ETHNIC GROUP
}

D0l: 10.36740/WLek202006122

\author{
Larysa A. Sarafinjuk', Olga P. Khapitska ${ }^{1}$, Nadiia M. Smolko ${ }^{1}$, Dmytro G. Smolko ${ }^{1}$, Larysa Ya. Fedoniuk², \\ Petro V. Sarafinjuk ${ }^{3}$, Iryna I. Matceyko ${ }^{3}$ \\ 'NATIONAL PIROGOV MEMORIAL MEDICAL UNIVERSITY, VINNYTSIA, UKRAINE \\ 2. HORBACHEVSKY TERNOPIL NATIONAL MEDICAL UNIVERSITY OF THE MINISTRY OF HEALTH OF UKRAINE, TERNOPIL, UKRAINE \\ ${ }^{3}$ VINNITSA STATE PEDAGOGICAL UNIVERSITY NAMED AFTER MIKHAIL KOTSYUBINSKY, VINNYTSIA, UKRAINE
}

\begin{abstract}
Introduction: The absence of diagnostic of the female sex organs in time can lead to serious disoders of the female athletes' reproductive system. There is few information in the literature about morphological evolution of the female sex organs, in particular, the uterus under the influence of sports.

The aim: To determine the peculiarities of linear sonographic dimensions of the uterus, its position and shape in the acrobats of the Ukrainian ethnic group of high level of sportsmanship in different periods of puberty.

Materials and methods: 122 acrobats of high level of sportsmanship and 126 girls who have not played sports were examined. The girls' passport age was between 8 and 21 years old. In order to determine belonging to the Ukrainian ethnic group, all surveyed girls were given questionnaires where they were required to indicate the nationality and place of birth of their parents and grandparents. All girls were devided into three groups according to their biological age: athletes of prepubertal period of ontogenesis, duting puberty and athletes of postpubertal period of ontogenesis.

Internal sex organs of all girls were examined by ultrasound diagnostic system of expert class Voluson 730 Pro (ATL, Austria) using a convex sensor RAB2-5L. The uterus was examined by the following program: determined its position and shape and 3 linear dimensions (length, width and thickness). The analysis of the obtained results was carried out in the licensed package Statistica 5.5 using nonparametric methods of estimation of indicators.

Results: The monitoring of the growth and development of the uterus in different ontogenetic periods in acrobats and women who are not involved in sports was analysed. We found, that the length of the uterus at all stages of puberty in acrobats was significantly less than in the girls of the control group. The width of the uterus was statistically significantly smaller in female athletes in the pre- and post-pubertal periods, and in puberty. The thickness of the uterus under the influence of acrobatic sports activity does not undergo significant changes in all periods of ontogeny.

Conclusions: Features of competitive activity in sports acrobatics as well as the result of sports selection lead to the delay of sexual development and, as a consequence, to the retardation of development of the uterus in all periods of puberty.
\end{abstract}

KEY WORDS: sonographic parameters of the uterus, sports acrobatics, periods of the puberty

Wiad Lek. 2020;73(6):1194-1198

\section{INTRODUCTION}

In order for the assessing of the health status of female athletes and the prediction of their reproductive capacity, it is important to analyse the morpho-functional parameters of female sex organs. Modern women's sport is characterized by a considerable intensity of physical activity, which have various effects on different organs and systems [1]. Sports acrobatics is marked by a whole set of exogenous factors that have a complex effect on the female body. First of all, to general sports groups children come in 5-6 years, in 7-8 year girls start their trainings in the groups of sports specialization. Secondly, trainings are as intensive physical activity, aimed at developing of flexibility, speed, and strength. Thirdly, girls have a special pecularities in diet with severe restrictions on food and water. Therefore, acrobats form a specific social-demographic group of the population, which requires constant medical control at pre-, pubertal and post-pubertal age [2]. The ontogenetic approach in studying of the features of the organism is based on the fact that within one calendar age there are individuals with different morpho-functional level of development [3]. This, first of all, is relevant for female athletes. Indicators of their biological age are the main criteria for assessing the condition of the whole organism $[4,5]$. Among the large number of methods for assessing biological age, the most commonly used are the stages of development of secondary sexual characteristics [6].

It should be noted that there are few notes regarding the morphological evolution of female sex organs. We have found publications concerning changes in the uterus and ovaries under the influence of intense loads during different puberty periods $[7,8,9,10]$. 


\section{THE AIM}

To determine the peculiarities of linear sonographic dimensions of the uterus, its position and shape in the acrobats of the Ukrainian ethnic group of high level of sportsmanship in different periods of puberty.

\section{MATERIALS AND METHODS}

Based on the Research Center of the National Pirogov Memorial Medical University,we conducted an examination of 122 acrobats of high level of sportsmanship, among them the first adult rank had 24 athletes, 38 girls were candidates for masters of sports, 46 - masters of sports, 14 - masters of international class sports. Experience in sports in all cases was more than three years. As a control group, 126 girls were examined, who were not engaged in sports and studied in schools of Vinnytsia. The girls' passport age was between 8 and 21 years old. The average calendar age had significant differences. In the prepubertal period of ontogenesis, acrobats had an average age (10.13 \pm 0.24$)$ years, and girls who have not played sports - (9,652 \pm $0,351)$ years; in puberty, acrobats had an average age (13.35 $\pm 0.32)$ years, control group $-(11.51 \pm 0.26)$ years; in the postpubertal period, acrobats had an average age (16.83 \pm $0.22)$ years, girls of the control group - (16.04 \pm 0.38$)$ years. In order to determine belonging to the Ukrainian ethnic group, all surveyed girls were given questionnaires where they were required to indicate the nationality and place of birth of their parents and grandparents.

To determine the biological age of the girls, we used the scheme [11], which is based on the determination of the stages of development of the hair in the axillae $(\mathrm{Ax})$ and the pubic $(\mathrm{P})$, the mammary glands $(\mathrm{Ma})$ and the age of the onset of the first menstruation (Me). The subjects were divided according to the degree of biological maturity into three groups:

1 - the prepubertal period (the appearance of pubic fishing), to it belonged 36 acrobats and 39 girls of the control group; 2 - pubertal period (puberty to the appearance of menarche), to it belonged to 31 acrobats and 35 girls of the control group; 3 - postpubertal period (fixed and ending puberty, the body reaches a definitive size), to it belonged 55 acrobats and 59 girls of the control group.

Internal sex organs of all girls were examined by ultrasound diagnostic system of expert class Voluson 730 Pro (ATL, Austria) using a convex sensor RAB2-5L. The uterus was examined by the following program: determined its position and shape and 3 linear dimensions (length, width and thickness). Measurement of the length and thickness of the uterus was performed during its longitudinal scan. The length is measured from the farthest point of the bottom of the body of the uterus to the projection of the inner throat, located in the corner between the body of the uterus and the cervix. Measurement of anterior-posterior size (thickness) was performed in the middle part of the uterus between the most distant points of the posterior and anterior walls. The uterine width was determined on the transverse ultrasound at the level of the tube angles. This section is perpendicular to that at which the thickness measurement was made [12].

The analysis of the obtained results was carried out in the licensed package Statistica 5.5 using nonparametric methods of estimation of indicators.

\section{RESULTS}

Using a method of non-invasive introscopy, such as ultrasound, we monitored the growth and development of the uterus during various ontogenetic periods in acrobats and women who are not involved in sports. We found that the athletes and girls of the control group in the prepubertal period of ontogenesis, the uterus is predominantly larger in size, however, it is already growing in width and thickness at this age. In some female athletes and girls in the control group, the cervix is not yet clearly visualized. However, in some cases it is possible to determine that it is about $2 / 3$ of the entire length of the uterus. The endometrium in girls of both comparison groups is poorly visualized or absent at all. In girls of this period, when analyzing the position and shape of the uterus did not reveal deviations of it norm, but it should be noted that in $18.3 \%$ of cases in acrobats the uterus has a cylindrical shape. The length of the uterus was $33.27 \pm 1.92 \mathrm{~cm}$ in girls in the control group, $29.67 \pm 2.14 \mathrm{~cm}$ in acrobats, and the difference between the comparison groups was significant $(p<0.05)$. We found that acrobats had a significantly smaller $(\mathrm{p}<0.05)$ uterine width $(22.62 \pm 2.94 \mathrm{~cm})$ compared to girls not involved in sports $(25.54 \pm 1.74 \mathrm{~cm})$. In the acrobatics group, the average value of uterine thickness $(11.99 \pm 1.52 \mathrm{~cm})$ is also smaller than the girls in the control group $(12.39 \pm 2.68 \mathrm{~cm})$, but the differences are not significant.

In puberty, uterine growth in length, thickness and width becomes more noticeable. At this age, girls clearly differentiate the cervix, begins to form an angle between the body of the uterus and the cervix. The ratio of the body of the uterus to the cervix is approximately $2: 1$, that is, the cervix is almost half the length of the body of the uterus. In $96.8 \%$ of female athletes of this period the shape of the uterus was normal, only $3.2 \%$ of acrobats had some deviations (uterus with two horns and uterus with partial intrauterine septum). The position of the uterus in the pelvic cavity in acrobats of puberty at $94.4 \%$ was normal (anteversio-anteflexio), when the body of the uterus is tilted forward and the angle between the body of the uterus and the cervix is also open in the front. In $5.6 \%$ of female athletes a retroversion was found when the body of the uterus was tilted back and the angle between its cervix and body also opened behind. There were no abnormalities in the uterine shape and position in the control group.

By comparing the macrometric size of the uterus between female athletes and non-athletic girls, we found significant differences in the pubertal period of ontogenesis. Thus, the length of the uterus in female athletes $(34.27 \pm 3.23 \mathrm{~cm})$ is significantly smaller $(\mathrm{p}<0.01)$ than in the control $(45.03 \pm 4.26 \mathrm{~cm})$. The width of the uterus in female athletes $(28.63 \pm 1.47 \mathrm{~cm})$ also tends to delay 
development ( $\mathrm{p}=0.057)$ compared to girls in the control group $(30.92 \pm 1.22 \mathrm{~cm})$. The thickness of the uterus makes no significant difference when comparing groups of acrobats $(18.64 \pm 0.76 \mathrm{~cm})$ and non-athletes $(18.27 \pm 1,91 \mathrm{~cm})$ of puberty.

Particularly rapid growth of the internal genitalia is observed with the onset of menarche. With the onset of menstrual function on the ultrasounds of acrobats and non-athletes, the uterus is predominantly pear-shaped. Analyzing the shape of the uterus, we found that $91.5 \%$ of female athletes did not have deviations, and in $8.5 \%$ of acrobats the shape of the uterus is not correct. In control girls in $94.6 \%$ of cases the shape of the uterus was correct and in $5.4 \%$ it was not correct. We defined such abnormalities as a uterus with a partial intrauterine septum, saddle-shaped uterus and uterus with two horns. The normal position of the uterus was observed in $89.09 \%$ of female athletes and in $98.31 \%$ of non-athletes.

We found that in the post-pubertal period, the length of the uterus in acrobats $(49.41 \pm 2.6 \mathrm{~cm})$ was statistically significantly smaller $(\mathrm{p}<0.001)$ than in girls of the control group $(56.97 \pm 3.19 \mathrm{~cm})$. The same pattern was established for the width of the uterus (the difference between the comparison groups is significant, $\mathrm{p}<0.01$ ): in acrobats its dimensions were $39.88 \pm 3.18 \mathrm{~cm}$, in control $-43.97 \pm 2.59 \mathrm{~cm}$. The thickness of the uterus, as in previous periods of biological development, has no significant differences. In acrobats its size was $28.48 \pm 3.63 \mathrm{~cm}$, in girls who did not play sports $-28.95 \pm 2.52 \mathrm{~cm}$.

\section{DISCUSSION}

Analyzing the features of prepubertal uterine development, we found that acrobats have significantly smaller uterine lengths and widths than non-sports girls. And this is despite the fact that the passport age in the group of female athletes is much lower than in the control group. It should be noted that the linear sonographic dimensions of the uterus that we have established meet the age standards. In researches of other scientists it is also determined that in the prepubertal period the uterus has cylindrical shape, the anterior-posterior size of the neck is equal to the anterior-posterior size of the body of the uterus. The length of the uterus is $2.5-4 \mathrm{~cm}$, the thickness is $1 \mathrm{~cm}$. The endometrium is not always vissible and only using large magnification $[13,14,15]$.

In our previous work, it was found that female athletes in the pubertal ontogenetic period had significantly lower $(p<0.05)$ calendar age compared to non-female athletes, indicating a significant re-certification of puberty in acrobatics, which, in our opinion, may be due to features sports selection and competitive sports activities [16]. Significant retardation in rates of puberty and biological maturity of female athletes has been found in other scientific studies $[17,18]$. It was found $[19]$ in female athletes $7-18$ years old who practice group acrobatics that the majority (68\%) of the surveyed belonged to the retardant type of development. The lag of biological age from passport to acrobatics averaged 2 years. We found that in the pubertal period of biological development, sonographic dimensions of the uterus under the influence of acrobatic sports activity are inhibited in development. Although a significant difference when comparing groups of female athletes and girls not involved in sports was found only for uterine length, they were $31.4 \%$ smaller than controls. In addition, it should be noted that the length of the uterus in acrobats is significantly smaller than the population norms characteristic of girls puberty. The authors note $[13,15]$ that in the pubertal period the uterus takes on the shapes and sizes of the adult women. The cervix is smaller than its body (1: 2-1: 3). The length of the uterus $-5-8 \mathrm{~cm}$, width $-3 \mathrm{~cm}$, thickness $-1.5 \mathrm{~cm}$.

We found that the width of the uterus in acrobats is the same as in the age of standards, but at the same time $7,99 \%$ less than the girls of the control group. In addition, in the acrobats of puberty period, we found deviations in the shape and position of the uterus, unlike the girls in the control group. In particular, in the group of female athletes was present cervix with two horns and uterus with a partial intrauterine septum and also uterus in position of the retroversio. The incidence of deviations in the shape and position of uterus in acrobats is in the norn of the intra-population variability, but the changes detected in female athletes require constant medical control.

In acrobats of the post-pubertal period of ontogenesis, we also found deviations in the shape of the uterus, the uterus with a partial intrauterine septum, saddle-shaped uterus and uterus with two horns. At $10,91 \%$ of acrobats and in $1,69 \%$ of non-sports women deviations in the position of a uterus were revealed. In acrobat group of post-pubertal period, except for retroversion, lateral version was detected in $2.3 \%$ of cases when the uterine body was tilted to the lateral pelvic wall. Such a high frequency of deviation of the position of the uterus, which is found in the acrobats, from our point of view, can be explained by the great physical exertion suffered by pre-school girls. Scientists also associate a high percent of reproductive disorders in female athletes with physical activity, which causes the to increasing of the production of androgens by adrenal glands in female body [17].

In the scientific literature there are data on disorders of the internal sex organs in $68.7 \%$ of the gymnasts, among which the most frequently revealed ultrasonic signs of chronic anovulatory cycle, inconsistency of the age norm of ultrasound parameters of the uterus and ovaries, sexual infantilevilus the ovaries. In non-sports girls, the number of violations was $27 \%$. Disorders of the reproductive system of female athletes are determined by a pathological condition called hyperandrogenia, which is caused by a change in androgen secretion and impaired metabolism $[2,20]$.

We found that in the post-pubertal period of ontogenesis, the length (by 15.3\%) and width (by 10.3\%) of the uterus in acrobats was statistically significantly smaller than in girls of the control group. L.V. Litisevich [2], studying the groups of elite sports gymnasts of different calendar age, also found that the length and width of the uterus in female athletes is much 
lower than the normal control values, in some cases up to $70 \%$, and an average of $50 \%$. In the group of girls 12,15 and 17 years she noted a slight decrease in uterine length relative to normal, and at the age of 14 and 16 years - an increase in uterine size relative to physiological parameters.

Summarizing the results of our study, it should be noted that, under the influence of acrobatic sports activities, the linear dimensions of the uterus (length and width) are not in the age standards, which can be a consequence of infantilism and retardation of puberty. Scientists consider such retardation of puberty as a consequence of the effects of hereditary factors, which are exacerbated by intense training, deficiency of the total body weight, in particular, its fat component [19]. In previous studies, we also found in acrobats a statistically significant decrease in body fat, which is indicated by the size of the endomorphic component of the somatotype, in all periods of ontogenesis [16].

Specialists of Vinnytsia National Medical University have established the constitutional conditionality of the development of organs of the female sex system [21] and proved the possibility of pubertal uterine bleeding appearance in girls due to the peculiriaties of the sonographic parameters of uterus and ovary [22].

Thus, the absence of diagnostic investigation of female sex organs organs in time, the absence of treatment of abnormalities in the future can lead to serious problems of the female athletes' reproductive system. A high diagnostic value and safety of ultrasound make this metod as a main method in the research of female athletes' sex organs.

\section{CONCLUSIONS}

1. At the pre-pubertal age, acrobats had shorter $(p<0.05)$ uterine lengths and widths than non-sport girls. In girls of both groups the position and shape of the uterus were in norm.

2. Acrobats at puberty had a smaller uterine length $(\mathrm{p}<0.01)$ and width $(\mathrm{p}=0.057)$. In $3.2 \%$ of acrobats was indicated abnormalities in the shape of the uterus (with two horns and with a partial intrauterine septum) and in $5.6 \%$ of female athletes the uterus retroversio was detected. There were no abnormalities in the control group.

3 . At the post-pubertal age, acrobats had significantly smaller uterine length $(\mathrm{p}<0.001)$ and width $(\mathrm{p}<0.01)$ than in girls of the control group. In $8.5 \%$ of acrobats and $5.4 \%$ of girls in the control group was identife the uterus with a partial intrauterine septum, saddle-shaped uterus and uterus with two horns. In $10,91 \%$ of acrobats and in $1,69 \%$ of non-sports women were revealed differences in the position of the uterus. In the group of acrobats, except for retroversion, in $2.3 \%$ of cases, lateral position was detected.

4. The uterine thickness in all periods of ontogenesis did not differ significantly between the acrobats and girls of the control group.

\section{REFERENCES}

1. Yakusheva Yu.I., Sarafynyuk L.A., Kyrychenko Y.V. Interralations of reocardiographic parametres of central hemodinamics with constitutional indicators by volleyball players of difderent positions. World of Medicine and Biology. 2015; 4 (53):96-102.
2. Liticevich L.V. Dannye UZ-issledovaniya organov malogo taza u devochek-sportsmenok [Ultrasound data of the pelvix organs in teenages girls athletes]. Reprodyktivnoe zdorovye detey i podrostkov. 2016; 3: 39-40 (In Russian).

3. Cumming S.P.,Standage M.V., LoneyT.C. etal.The mediating role of physical self-concept on relations between biological maturity status and physical activityin adolescent females. Journal of Adolescence. 2011;3(34):465-473.

4. Cairney J., Veldhuizen S., Kwan M., Hay J., Faught B. Biological age and sex-related declines in physical activity during adolescence. Med. Sci. Sports Exerc. 2014; 4(46): 730-735.

5. Freitas A.S., Figueiredo, A.J., de Freitas A.L., Rodrigues V.D., da Cunha A.A., Deusdará F.F. Silva M. J. Biological Maturation, Body Morphology and Physical Performance in 8-16 year-old obese girls from Montes Claros. MG. J. Hum. Kinet. 2014; 43:169-176.

6. Linpei J., Weiguang Z., Xiangmei C. Common methods of biological age estimation. Clin. Interv. Aging. 2017; 12:759-772.

7. Khmara T.V., Zamorskii I.I., Ryznychuk M.O., Kryvchanska M.I., Boichuk O.M., Dmytrenko R.R. Peculiarities of prenatal vagina morphogenesis. Wiad. Lek. 2019; 1(72):72-78.

8. Kuzniak N., Protsak T., Marchuk 0., Fedoniuk L., Kamyshnyi A., Penteleichuk N., Stoliar D., Dmytrenko R. Histotopography of the 0viducts in Fetus. Wiad. Lek. 2019; 8(72):1481-1485.

9. Khmara T.V., Ryznychuk M.0., Sarafyniuk L.A., Kryvchanska M.I., Biriuk I.Г. The peculiarities of the prenatal morphogenesis of the epididymis. World of Medicine and Biology. 2018; 3(65):199-204.

10. Koval H, Chopiak V, Kamyshnyi A. mRNA TLR2 and TLR4 expression in the endometrium tissue in women with endometriosis assosiated with infertility. Georgian Med News. 2015; 244:7-11.

11. Avtandilov G.G. Medicinskaya morfometriya [Medical morphometry]. Moscow: Medicine, 382p. (In Russian).

12. KylakovV.I., Kyznetsova M.N., Martush N.S. Ultrazvukovaya diagnostika v ginekologii detskogo i podrostkovogo vozrasta [Ultrasound investigation in the gynecology of the childs and at the juvenile age]. - Moscow: Medicine. 1994, 112 p. (In Russian).

13. Delyagin V.M., Myasnikov S.V., Toniyan K.A., Senyakovich N.B., Dyaduk T.G Ultrazvukovyeissledovaniya malogo taza u devochekidevushek-podrostkov SonoAce Ultrasound [Ultrasound investigation of the pelvix at girls and teenages SonoAce Ultrasound]. Moscow. 2011;22:78-87. (In Russian).

14. Herter L., Golendzimer E., Flores J. Et al. Ovarian and uterine sonography in healthy girls between 1 and 13 years old: correlation of findings with age and pubertal status. American Journal of Roentgenology. 2002;178:1531-1536.

15. Razzaghy-Azar M., Ghasemi F., Hallaji F. et al. Sonofraphic measurments of uterus and ovaries in premenacheal healthy girls between 6 and 13 years old: correlation with age and pubertal status. Journal of Clinical ultrasound. - 2010 (http://www.ncbi.nlm.nih.gov/ pubmed/20572067).

16. Sarafinyuk L.A., Khapitska O.P., Yakusheva Yu.I., Ivanytsia A.O., Sarafinyuk P.V. Somatotypological features of acrobat girls in different periods of ontogenesis. Biomedical and biosocial anthropology. 2018; 32:43-47.

17. Bacciotti S., Baxter-Jones A., Gaya A., Maia J.The physique of elite female artistic gymnasts: a systematic review. J. Hum. Kinet. 2017; 58:247-259.

18. Erlandson M.C., Mirwald R.L., Sherar L., Maffulli N. Growth and maturation of adolescent female gymnasts, swimmers, and tennis players. Medicine \& Science in Sports \& Exercise. 2008; 1(40):34-42.

19. Davydov V. Yu., Antonova E. A., Vrublevsky E. P. Estimates of the main aspects of the prospects of young athletes in acrobatics. Physical culture, sports and health of the nation. 2013; 15:311-317. 
20. Fedonyuk L. Ya., Oleshchuk A.M., Sas L.M., Boyarchuk O.R., Mukolenko A. Z., Orel Yu. N., Glushko K.T. Polipragmaziya: ot pediatrii k geriatrii [Polypragmasy: From paediatrics to geriatrics]. Voprosy Prakticheskoi Pediatrii. 2018; 13(1):77-82. (In Russian).

21. Chaika G.V., Prokopenko S.V., Kucherenko 0.M. Modeling possibility of uterine bleeding puberty in girls depending on the characteristics of sonographic parameters uterus and ovaries. World of Medicine and Biology. 2015; 4(53):84-87.

22. Tkachenko M. M., Prokopenko S. V., Cherkasova L. A. Modeling possibility of uterine bleeding puberty in girls depending on the characteristics of sonographic parameters uterus and ovaries. World of Medicine and Biology. 2016; 4(58):66-71.

The work is carried out within the framework of the initiative research work of the E. Pirogov Vinnitsa National Medical University (Vinnitsa, Ukraine) register number 0115 U001168 "To develop the predictional models of the pubertal uterine bleeding and algodysmenorrhea in girls, depending on the constitutional features of the body".

\section{ORCID and contributorship:}

Larysa A. Sarafinjuk - 0000-0001-8253-5997 D,B,C,F

Olga P. Khapitska - 0000-0002-1333-5892 E,D

Nadiia M. Smolko - 0000-0001-6534-040X ${ }^{D}$

Dmytro G. Smolko - 0000-0003-4694-9396 ${ }^{A}$

Larysa Ya. Fedoniuk - 0000-0003-4910-68 88 E,F

Petro V. Sarafinjuk - 0000-0002-6795-1279 A,D

Iryna I. Matceyko - 0000-0002-2656-6200 ${ }^{B}$

\section{CORRESPONDING AUTHOR Larysa A. Sarafinjuk \\ National Pirogov Memorial Medical University \\ 56, Pirogova Str., Vinnytsia, 21018, Ukraine \\ tel: +380674300853 \\ e-mail: I.sarafinyuk@gmail.com}

Received: 22.02 .2020

Accepted: 08.05 .2020 